\title{
ГЕОГРАФИЯ РАЗВИТИЯ РЕГИОНАЛЬНЫХ ТРАНСПОРТНО-ЛОГИСТИЧЕСКИХ КОМПЛЕКСОВ И ФАКТОРЫ ДОСТУПНОСТИ
}

\author{
(c) 2021 Сикиринская Каролина Александровна \\ заместитель директора российско-итальянского центра \\ Института государственной службы и управления \\ Российская академия народного хозяйства и государственной службы \\ при Президенте Российской Федерации, Россия, Москва \\ E-mail: sikirinskaya-ka@ranepa.ru
}

(c) 2021 Панова Татьяна Владимировна

кандидат экономических наук, декан факультета Международного регионоведения

и регионального управления Института государственной службы и управления

Российская академия народного хозяйства и государственной службы

при Президенте Российской Федерации, Россия, Москва

E-mail: tv.panova@igsu.ru

На сегодняшний день транспортная доступность является одним из краеугольных камней территориального развития регионов. Исторически наличие транспортной системы служило одним из основных критериев развития того или иного региона. Несомненно, если мы говорим о наличии транспортной инфраструктуры в регионе и ее функционировании, то можно представить ее в виде кровеносной системы организма, которая насыщает каждую клетку необходимыми для жизнедеятельности элементами. Итак, транспортная инфраструктура, формирует некий каркас макрорегиона и ее развитие оказывает влияние не только на конкретную часть, но и распространяется на прилегающие территории, которые начинают функционировать, совместно создавая синергию социальных и экономических благ. Для того, чтобы дать оценку региональному развитию транспортно-логистической сети в регионе, необходимо рассмотреть ряд факторов, влияющих на данный процесс.

Ключевые слова. Транспортно-логистический комплекс, неравенство регионов, транспортная доступность, логистика, экономическая география, внешнеторговые отношения, торговая политика, социально-экономическая безопасность, мировая экономика, устойчивое развитие общественного транспорта.

В базовой экономической теории, существует единый постулат о приумножении конкурентных преимуществ той или иной страной, что становится золотым правилом развития экономических процессов для выхода на международные рынки сбыта, оставаясь конкурентноспособным. В классической экономической теории основным преимуществом служила ресурсная база, однако с развитием теории экономической мысли и сплетения глобальных экономических систем и подсистем, под преимуществом стали понимать и приобретённые ресурсы, которые были созданы человеком и грамотно эксплуатироваться. Природные ресурсы имеют свойства истощатся и поэтому их необходимо постоянно поддерживать и вкладывать инвестиции для продуцирования новых технологических опций в данной отрасли. Многие государства выбира- ют путь исключительной эксплуатации сырьевых запасов не трансформирую при этом ничего нового. Существует и еще один не маловажный аспект - это развитие территориального ресурса. Так, исторически борьба за расширение пространственных границ была основой государственного могущества. Территориальный аспект и борьба за пространство исторически становится основным лейтмотивом к развитию ресурсной составляющей. Однако, территория не единственное зерно, которое должно прорасти, чтобы создать что-то масштабное и новое, многие страны, не обладающие столь большим пространственным потенциалом, очень грамотно выстраивают приоритеты и развиваются в тех условиях и с теми ресурсами, которые имеют в наличии, превращая недостающие элементы в уникальный продукт. Одним из примеров та- 
кого продукта является транспортная сеть Европы, которая превосходит транспортную инфраструктуру России. Так, густота транспортной сети или ее плотность в Западной Европе составляет 160 км/100 квадратных км и занимает первое место в мире по обеспеченности транспортными линиями. Локомотивами, несомненно, являются Англия, Германия и Франция. В России по европейским меркам транспортная сеть является достаточно развитой, однако по сравнению с обширной территорией, транспортная сеть РФ имеет видимые диспропорции. Хотелось бы отметить, что по дальности перевозок европейская система сильно уступает России и США, например, однако основное преимущество это развитая инфраструктура и технологическая обеспеченность всех регионов Европы транспортной составляющей.

Несмотря на то, что Россия геополитически оказывается в очень территориально выгодном положении хартленда, она имеет рад минусов, так например, выход к морским транспортным линиям становится заблокированным для большинства регионов, а часть имеют выход к морским линиям, которые по признаку сезонности не будут функционировать большую часть года; погодные условия северной части России также блокируют непрерывный перевозочный процесс, а развитие инфраструктуры в данных регионах или требует высоких капиталовложений, которые не будут окупаемы, или невозможно совсем. Поэтому основой для территории РФ служит железнодорожный и автомобильный вид транспорта, если говорить о городском виде транспорта, то его тоже важно учесть при пассажирских перевозках. Из-за ряда проблем, которые возникают из-за неравенства развития транспортной инфраструктуры, стоит затронуть термин «транспортной доступности». Недостаток капитальных вложений и исторически неблагоприятные условия породили ряд современных проблем, транспортная сеть, например, оказалась полностью раздробленной. Распад СССР только ухудшил состояние транспортной инфраструктуры, разорвав выстроенный годами механизм и мирохозяйственные связи, которые не удалось восстановить и сегодня. В Европе же изначально транспортные сети строились как единый механизм с четким направлением и правильным стратегическим расчетом, а также возможностью подвода при объединении транспортных линий с другими регионами. Историче- ски же самые богатые регионы были именно те, которые становились торговой Меккой за счет географически выгодного положения на пересечении нескольких регионов, что позволяло создать центр товарообмена или с выходом к морским портам, что также позволяло перенаправлять товары в другие регионы, становясь посредником в торговом обмене.

В условиях глобализации и интернационализации торговых процессов условия поставки товаров и оборота внешнеторговой деятельности стали еще больше зависеть от транспортной инфраструктуры. Транспортная отрасль является одной из ключевых составляющих экономики и основным двигателем торговых процессов. С этой точки зрения, следует вывод, что территория с менее развитыми условиями для транспортной инфраструктуры, не может развиваться на ровне с регионами, в которых существует территориальный потенциал развития обширной транспортной сети. При этом не стоит путать понятия «логистика» и «транспорт». Логистика сама по себе не является залогом преимущества, прежде всего это часть науки об управлении. Логистика является частью теории менеджмента, поэтому транспортно-логистическая сеть состоит из нескольких элементов - это рационального использования территориальных ресурсов для построения правильной и надежной инфраструктуры. С другой, управления и правильного расположения не только самой транспортной сети, но и ее связующих элементов. Транспорт как один из ключевых факторов развития региональной экономики России будет иметь несколько ключевых задач:

- во-первых, развитие транспортной инфраструктуры позволяет поддержать и упростить деятельность предприятий, обеспечив географическую доступность к факторам производства и каналам дистрибуции. Как следствие, укрупнение деятельности предприятий в регионе будет способствовать увеличению рабочих мест, притоку инвестиционного капитала, привлечению новых товарных потоков и увеличению благосостояния региона в целом. На международном уровне постепенное развитие отдельных звеньев одной инфраструктурной сети приведёт к нивелированию «узких» мест на пути транзитных перевозок и увеличит пропускную способность грузов.

- во-вторых, развитие транспортнологистических услуг, как самостоятельной от- 
расли не только будет приносить доходные поступления в Федеральный бюджет Российской Федерации, но и позволит автоматизировать работу всего транспортно-инфраструктурного комплекса. Сегодня, рынок услуг получает активное развитие как отдельный вектор деятельности, от которого по цепной реакции будет зависеть эффективность работы: складских помещений, транспорта, транспортного обслуживания, маркетингового рынка, производственного комплекса и многое другое. Поэтому, транспорт отдельно от логистики не будет функционировать полноценно, но самое главное, наличие только транспорта не даст доходности и развития экономическому процессу.

Очень важно понимать отраслевую направленность региона, поскольку от этого фактора будет зависеть степень чувствительности той или иной отрасли к развитию транспортной деятельности. Поскольку для одного региона транспорт будет являться дополнением инфраструктуры (поскольку важна именно качественная и мобильная транспортная сеть) а для другого играть стратегическую роль для экономики региона. В связи с данным условием выделяют три группы отраслей [1].

В первой группе, находятся те отрасли, для которых транспортно-логистическая система играет ключевую роль. В основном те виды деятельности, которые смогут перераспределить спрос на рынки смежных регионов за счёт снижения транспортных расходов и более мобильной транспортной инфраструктуры с целью ускорения процесса доставки. В основном это предприятия обрабатывающей промышленности и занимающиеся наукоёмким производством с высокой долей транспортных расходов (около 10\%).

Во второй группе, окажутся отрасли, которые способны перераспределить свою продукцию на экспорт по конкурентным ценам и являются менее чувствительными к транспортным системам.

K третьей группе, относятся предприятия, которые ориентированные на локального потребителя рынок, где задействованы перевозки на короткие расстояния. В основном это розничная торговля и компании, которые оказывают местные деловые услуги.

Чтобы проследить закономерность влияния транспортного развития на основные экономические показатели, необходимо выделить ключевые факторы [2]:
1) Степень влияния транспорта на доступность рынков ресурсов и сбыта. Данный фактор обуславливает снижение затрат и временного интервала на процесс перевозки, а также оказывает положительное влияние на доступность рынков. Такой эффект позволяет смежным регионам и отдельным предприятиям при тех же производственных условиях извлекать больше прибыли, а значит повышать конкурентоспособность конечной продукции. При этом от наличия развитой транспортной инфраструктуры выигрывает самый широкий спектр предприятий, поскольку товарные потоки начнут конкурировать за использование транспортных мощностей, тем самым увеличивая спрос на перевозки разного уровня: международного, национального, регионального. Соответственно, для более крупных регионов основную роль будут играть международные сообщения, для более мелких регионов внутрирегиональные потоки, которые будут обеспечивать постоянную загрузку. Таким образом, в зависимости от степени доступности региональных транспортных систем, основные показатели рентабельности будут влиять на социальное благосостояние людей.

2) Итоговые расходы на транспорт в конечной цене товаров. Оценить транспортные затраты можно через методы оценки: адвалорных затрат по географическому расстоянию П. Самуэльсона; оценки применимых базисных условий; фрахтовых расходов по П.-Ф. Комбу и М. Лафуркаду (или тарифов). Уменьшение транспортных расходов - это необходимое условие эффективной международной торговли. Таким образом, выгоды от осуществления торговли будут выше, чем транспортные расходы.

3) Уровень инвестиционной активности в регионе. Инвестиционные поступления в развитие транспортной инфраструктуры приводит к повышению стоимостных показателей на рабочую силу и ресурсы, которые используются в производственном процессе. Огромную роль играет разница между государственным софинансированием или политикой субсидирования, и частными инвестициями, которые оказывают разный эффект. Мультипликативный эффект государственных вложений имеет позитивное влияние и на частные инвестиции рождая спрос. Важную ремарку сделал американский экономист С.Харрис, он определял, что важно инвестировать именно в транспортную инфраструктуру региона, чтобы грузы не проходили только транзитом, что окажет лишь негативное 
влияние на регион и переформирует его в транспортный придаток.

4) Выгодное географическое размещение транспортной инфраструктуры по отношению к социальным объектам и производственным комплексам. Трансформация пространства региона в зависимости от транспортной инфраструктуры будет влиять на формирование межнациональных производственных сетей в результате разделения труда.

Таким образом, развитие региональных транспортных систем (РТС) будет оказывать влияние на смежные регионы, следовательно, по цепочке обеспечивать связь с периферийными регионами и изменять структуру транспортных затрат на отдельных маршрутах [3].

Необходимо отметить, что развитие региональных транспортных систем имеет комплексное значение для экономического благосостояния региона как на микроуровне, если оценивать влияние на домашние хозяйство и фирмы, так и на макроуровне обеспечивая стабильное регулирование внешнеэкономической деятельности. В свою очередь, региональное экономическое развитие будет служить основным экономическим рычагом для увеличения спроса на региональную продукцию и услуги перевозки. Таким образом, целесообразно рассмотреть несколько вариантов развития региональных транспортных систем Российской Федерации.

Существуют также различные методы оценки региональной экономики:

- Системный анализ. Характеризуется изучением отдельных структур, отрасли народного хозяйства, связи и взаимодействие между ними;

- Метод систематизации. Изучает и систематизирует полученные результаты;

- Балансовый метод. С помощью отчётных балансов по тем или иным показателям, определяет рациональный уровень развития региона по отраслям;

- Картографический метод. Помогает наглядно оценить особенности размещения отдельных отраслей хозяйства;

- Метод экономико-географического исследования. Включает три формы: региональный изучает формирование, развитие, размещение общественного производства по регионам, отраслевой - размещение, формирование и развитие отраслей народного хозяйства и местный - развитие и формирование производства в отдельном городе или поселке;

- Метод экономико-математического мо- делирования. С помощью электронных средств обрабатывает большие массивы статистических данных, которые являются основной для анализа региона.

В конечном итоге в региональной экономике выделяют несколько функций: уровень отраслевой производительности; ценообразование на товары и услуги; распределение товаров и услуг по сформированным каналам дистрибуции; потребление готовых товаров и услуг внутри региона. Таким образом, экономическое пространство можно разделить на несколько подуровней макро- (пространство страны в целом), мезо(пространства региона внутри страны), микро(пространство фирм и предприятий в регионе) уровни [4]. Соответственно, с экономической точки зрения пространство будет рассмотрено как пределы действия основных хозяйственных потоков. Основной задачей при таком анализе будет определение природы совокупности хозяйствующих субъектов, и определить ее особенности в данном пространстве [5].

Для дальнейшего рассмотрения влияния экономического пространства на транспортнологистический комплекс, необходимо взять во внимание штандортную концепцию экономического пространства. Данная концепция была рассмотрена как транспортный фактор в теории размещения производства, немецким экономистом Вильгельмом Лаунхардтом как определяющий [6]. Им был разработан метод локационного треугольника для решения задачи минимизации транспортных издержек и роста экономического благосостояния региона, который находится на пересечении основных пространственных связей.

Согласно его теории, логистика берёт своё начало от рациональной организации логистики производственного цикла. Так, согласно теории, производство скоропортящихся, тяжелых и объемных товаров должно располагается вблизи города, а скотоводство, для которого транспортные расходы на единицу по сравнению с издержками производства на единицу земли невелики, размещается на границе региона [7].

Таким образом, экономист определил, что спрос должен линейно зависеть от цены доставки: количество проданных товаров одного производителя прямо пропорционально кубу транспортных расходов на доставку от фирмы до окружности границы зоны, где находится рынок, и обратно пропорционально квадрату транспортных тарифов (Рисунок 1). 


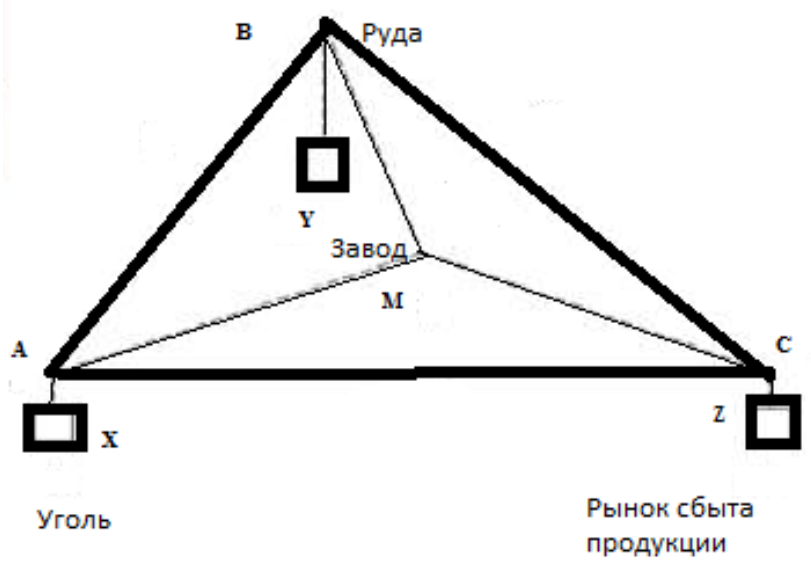

Рисунок 1. Локационный треугольник Лаунхардта

Источник: Теории структуризации и эффективной организации экономического пространства // Файловый архив студентов StudFiles URL: https://studfiles.net/preview/3173470/ (дата обращения: 13.05.2020)

Подводя итоги вышесказанному, можно чётко увидеть пропорциональную зависимость между расположением производственных центров и транспортной инфраструктуры, чтобы снизить издержки на единицу продукции за счёт сокращения удалённости [8]. Если же мы рассматриваем укрупнённый регион с точки зрения государства, то важно отметить, что фактор производства, складские помещения и основные транспортные узлы эффективны при низкой удалённости от смежной с другими государствами или регионами границы [9].

Таким образом, для развития региону необходимо постоянное развитие инноваций. Восприимчивость региона к инновационной сфере напрямую зависит от развития социальноэкономических отраслей региона. Как уже отме- чалось ранее, транспортно-логистический комплекс включает в себя сразу несколько факторов развития и включает структуру нескольких рынков сразу. Можно сказать, что транспортная логистика это некая совокупность экономических и социальных факторов способствующих развитию региональных систем и подсистем обеспечивая непрерывное движение материальных потоков и их управление. Чтобы оценить логистический потенциал транспортной логистики необходимо обратиться к различным методикам расчета и определить уровень транспортнологистической составляющей в экономической структуре региона, тем самым выявить потенциал развития данного региона с помощью повышения транспортно-логистической доступности.

\section{Библиографический список}

1. Прокофьева Т.А., Лопаткин О.М.Логистика транспортно-распределительных систем: региональный аспект.- М.: РКонсульт, 2003.- С. 57-90.

2. Вардомский Л.Б. Экономическое взаимодействие стран-членов СНГ в контексте евразийского экономического проекта. .- М.: ИЭ РАН, 2015.- С.136-170.

3. Вардомский Л.Б., Пылина А.Г. Внешнеэкономические связи постсоветских стран в контексте евразийской интеграции.- М.: ИЭ РАН, 2014.- С.72-92.

4. Поляк Г. Б. Региональная экономика: Учебник.- М.: ЮНИТИ, 2015.-С. 140-193.

5. Носова С. С. Региональная экономика. Основы теории и методы исследования.- М.: КноРус, 2013.- С. 8993.

6. Головин В. А. Основы кластерной теории развития региона. // Рыночная трансформация экономики России: проблемы, перспективы, пути развития (IV Всероссийская научно-практическая конференция).- М.: ИНФРА-М, 2015.- С. 19-23.

7. Асаул, А.Н.Этногеографические факторы глобализации и регионализации мира.- М.: ИПЭВ, 2017.- С. 157-159.

8. Климов А. А. Пространственное развитие и проблемные территории. Социально-экономические аспекты.М.: КомКнига, 2016.- С. 17-58.

9. Спартак А.Н. Международная торговля услугами: новые тенденции развития и регулирования, роль в интеграционных процессах - М.: ВАВТ, 2016.- С. 34-78. 